\title{
Alterações hematológicas observadas em eqüinos submetidos a laparotomia em estação e enterotomia do cólon menor
}

\author{
Hematological evaluation of horses after standing laparotomy and small colon enterotomy

\begin{abstract}
Thomaz Guimarães Montello ${ }^{1}$, J arbas Francisco da Costa Castro J r. ${ }^{2}$, Valesca Peter Santos ${ }^{1}$, Elisabeth Caldas Soares Christo ${ }^{3}$ \& Antônio de Pádua Ferreira da Silva Filho ${ }^{4}$
\end{abstract}

\begin{abstract}
RESUMO
As afecções abdominais do eqüino requerem freqüentemente a utilização de técnicas cirúrgicas para sua resolução. A magnitude destes procedimentos associada ao estresse anestésico levam a alterações sistêmicas importantes. Neste estudo foram avaliadas as alterações na celularidade hematológica causadas por laparotomias em estação, concomitantes com enterotomias do cólon menor. A laparotomia foi realizada pelo flanco esquerdo, com os animais sob sedação (cloridrato de romifidina, $80 \mathrm{mg} \cdot \mathrm{kg}^{-1}$ ). Foi realizado bloqueio com lidocaína a $2 \%$ na linha de incisão e bloqueio do nervo torácico lateral. As enterotomias foram procedidas na tênia ante-mesentérica do cólon menor. Após a manipulação e enterorrafia, a alça foi recolocada na cavidade abdominal, sendo feita a sutura da parede. As colheitas de sangue foram realizadas no tempo précirúrgico imediato e em três colheitas subseqüientes a cada 24 horas. Foram contados o número de eritrócitos, de leucócitos, os neutrófilos bastonados e segmentados e o percentual de hematócrito. Também foram verificadas as alterações nas concentrações de hemoglobina, proteína e fibrinogênio plasmáticos. Os valores de eritrócitos e hemoglobina elevaram-se significativamente. As concentrações plasmáticas de proteína e fibrinogênio sofreram elevações significativas, assim como o número de leucócitos e a quantidade de neutrófilos bastonados. Concluiu-se que a resposta celular e dos demais constituintes hematológicos foram compatíveis com um quadro inflamatório agudo, o qual poderia estar compatível com um processo infeccioso, porém sem correspondência clínica.
\end{abstract}

Descritores: eqüinos, laparotomia, hematologia.

\begin{abstract}
The horse abdominal pathologies often needs surgical techniques to your complete resolution. This kind of procedure, usually a big trauma plus the anesthetic stress very important in horses, bring important systemic changes. At this work were evaluated the changes in blood constituents (cells and other components) generated by standing laparotomies followed by small colon enterotomies. The approach was made in left flank after sedation of horses with romifidine clorhidrate ( $80 \mathrm{mg} \cdot \mathrm{kg}^{-1}$, intravenously). The incision line in abdominal wall was infiltrated with $2 \%$ lidocaine in two different deep layers. The lateral thoracic nerve was blockade with $2 \%$ lidocaine too. The enteromies were made in ant mesenteric band of small colon. After exposition of intestinal loop, enterotomy and suture, the viscera was replaced to abdominal cavity, following the wall suture. The venous blood samples were obtained immediately before the surgical intervention and each subsequent 24 hours, for 3 days. The cell count used erythrocytes, leucocytes, basto neutrophyls and packed cell volume. The plasmatic concentration of protein, fibrinogen and hemoglobin were measured too. Variations in erythrocytes and hemoglobin results in an arise with statistic significance. The values of protein and fibrinogen as well leucocytes and bastoned neutrophils showed statistic differences. It was concluded that the cells and other values changed in a way to demonstrate an acute inflammatory pathology, compatible with an infectious syndrome, however without match with clinical status of healthy showed by horses.
\end{abstract}

Key words: horses, laparotomy, hematology. 


\section{INTRODUÇÃO}

Algumas desordens gastro-intestinais do eqüino ocorrem ou progridem na forma de afecções que requerem intervenções cirúrgicas, sendo a severidade da dor abdominal e a distensão fatores indicativos da necessidade de cirurgia $[10,11,18]$. A maioria dos casos referidos como alterações do cólon menor requerem intervenções cirúrgicas,sendo os enterólitos a ocorrência mais comum nos animais com idade entre cinco e 10 anos [7]. A incisão na banda ante-mesentérica promove menor hemorragia, melhor coaptação, menor tempo cirúrgico, menor reação inflamatória e a ocorrência de suturas mais resistentes [2].

A evolução das técnicas de contenção química proporcionaram ao clínico um complemento de diagnóstico que seria a laparotomia exploratória. Neste particular, a laparotomia exploratória em estação constituiu-se em um instrumento eficaz e relativamente inócuo [6] no manejo da dor abdominal em eqüinos. $\mathrm{O}$ procedimento cirúrgico através da fossa paralombar esquerda foi utilizado para abordagem de segmentos do íleo, partes do cólon menor e o ovário esquerdo nas fêmeas por [3,4].

A concentração de fibrinogênio plasmático é um indicador não específico de diagnóstico e prognóstico de processos inflamatórios em eqüinos sendo que elevações são expressões sensíveis da ocorrência de agressão tecidual e, podem revelar alterações dissociadas de participação infecciosa [5,14]. Foi demonstrado em equiinos com peritonite que $43 \%$ deles apresentaram leucocitose com neutrofilia [9].

O objetivo deste estudo foi definir a magnitude das variações promovidas pela laparotomia associada ou não à realização de enterotomias do cólon menor nos parâmetros hematológicos.

\section{MATERIAIS E MÉTODOS}

Foram utilizados 07 animais de diferentes raças, com idades variando entre dois e seis anos, de ambos os sexos. Os animais ficaram alojados previamente e no período pós-operatório no Hospital Veterinário Dr. Joaquim Araújo do Jockey Club do Rio Grande do Sul.

O protocolo anestésico utilizou cloridrato de romifidina, $80 \mu \mathrm{g} . \mathrm{kg}^{-1}$ (Sedivet $\left.{ }^{\circledR}\right)$ via intravenosa. Após contenção em tronco de ferro tubular tricotomia e antisepsia do flanco esquerdo, foi realizada anestesia lo- cal, na linha de incisão. Aproximadamente cinco centímetros a partir da última costela, foi estabelecida uma linha vertical de bloqueio. Outro ponto de bloqueio foi obtido a partir de uma infiltração perineural do nervo torácico lateral, sendo utilizada em ambos os pontos lidocaína a 2\% (Xylestesin $®$ ).

Foram procedidas colheitas de sangue por venipunção da jugular esquerda em tubos com EDTA sódico para realização de hemograma. Duas alíquotas de plasma foram processadas para dosagem de proteínas totais e fibrinogênio plasmático por refratometria. Os demais valores avaliados foram o hematócrito, a contagem de eritrócitos, a concentração de hemoglobina e a contagem leucocitária (com contagem diferencial). As amostras foram processadas no Laboratório de Análises Clínicas do Hospital Veterinário Joaquim Araújo.

As amostras de sangue foram colhidas imediatamente antes de cada intervenção $(\mathrm{P})$ e nas 24 horas subseqüentes, por três dias (24, 48 e 72 horas).

Os dados obtidos foram expressos em média \pm desvio padrão. As médias entre tempos de colheita e entre os grupos foram comparadas pelo teste $t$ de Student, considerando como significativo quando $\mathrm{p}<$ $0,05[12]$.

\section{RESULTADOS}

\section{Aspectos clínicos e cirúrgicos}

O cloridrato de romifidina na dose de 80 $\mathrm{mg} \cdot \mathrm{kg}^{-1}$ por via intravenosa, produziu sedação efetiva em todos os animais utilizados neste experimento.A técnica utilizada para bloqueio anestésico local e troncular permitiu o desenrolar de todo o experimento sem intercorrências que colocassem o paciente, a intervenção ou o cirurgião em risco, sendo utilizado um tempo máximo de 80 minutos por intervenção.O acesso cirúrgico através da fossa paralombar esquerda permitiu uma abordagem adequada de todas as camadas previstas desde a pele até o peritônio. A localização, exteriorização e a manipulação da víscera alvo do projeto ocorreram de forma fácil e sem problemas. Em todos os animais operados a cicatrização ocorreu sem problemas e sem cuidados especiais além da limpeza diária e aplicação de antisépticos. Todos os animais utilizados neste experimento sobreviveram. 


\section{Aspectos hematológicos}

Os valores médios do número de eritrócitos, concentração de hemoglobina e hematócrito obtidos a partir das amostras de sangue total em todos os tempos previstos estão dispostos Tabela 1. No número de eritrócitos foi observada uma elevação significativa entre a amostra basal $(\mathrm{P})$ e aquela obtida no intervalo de 24 horas. Igual variação foi detectada na dosagem de hemoglobina. $\mathrm{O}$ valor de hematócrito não diferiu significativamente entre os tempos de colheita.

O número de leucócitos elevou-se significativamente a partir da colheita correspondente às 24 horas pós-intervenção, manteve-se próximo na colheita das 48 horas e declinou na última amostra. Todos os tempos pós-cirúrgicos diferiram significativamente da colheita basal. A realização de laparotomia associada à enterotomia elevou significativamente a contagem de neutrófilos bastonados, sendo registrado já nas 24 horas posteriormente à intervenção. Foi detectada uma redução na segunda colheita, porém com valores ainda superiores à basal. Na última colheita, apesar da queda sensível em relação às 24 horas, a quantidade contada ainda era diferente do período inicial. O valor da terceira colheita diferiu do obtido na primeira colheita póscirúrgica. A variação percentual nos neutrófilos segmentados foi estatisticamente significativa a partir das 24 horas pós-intervenção. Os valores permaneceram diferentes do valor basal em todos as colheitas posteriores à cirurgia, sem diferirem entre os tempos. Os valores médios encontram-se na Tabela 1.
A concentração das proteínas plasmáticas elevou-se significativamente passadas 24 horas da intervenção cirúrgica no grupo Enterotomia. $\mathrm{O}$ valor declinou nas 48 e 72 horas, mas permaneceu ainda superior no último período em relação ao inicial. A concentração de fibrinogênio plasmático variou significativamente apenas na colheita das 72 horas onde houve uma elevação. Os valores médios encontram-se na Tabela 1.

\section{DISCUSSÃO}

A laparotomia em estação mostrou-se técnica viável e de baixo custo [19]. O tempo cirúrgico e o espaço criado para a abordagem da cavidade abdominal foram suficientes para a localização e manipulação das alças que interessavam ao trabalho. Enterotomias no cólon menor mostraram-se de fácil realização em virtude da adequada exposição visceral proporcionada pela abordagem do flanco esquerdo [3]. Os procedimentos de anestesia local e perineural utilizados foram considerados satisfatórios uma vez que permitiram a realização das cirurgias sem movimentos ou reações dos pacientes.

A técnica de anestesia com lidocaína apenas no local da incisão com resultados excelentes em todos os animais contrasta com outros relatos [16] que consideraram a anestesia paravertebral boa em dois animais e apenas boa em outros seis. A utilização da anestesia perineural do nervo torácico lateral pareceu trazer a vantagem de uma menor reação do paciente aos estímulos cutâneos [15].

Tabela 1. Número de eritrócitos (células. $10^{6} \cdot \mathrm{mm}^{3-1}$ ), leucócitos (células.mm $\mathrm{m}^{3-1}$ ), neutrófilos bastonados (\%) e segmentados $(\%)$, concentração de hemoglobina $\left(\mathrm{g} \cdot \mathrm{dL}^{-1}\right)$, concentração plasmática de proteínas $\left(\mathrm{g} \cdot \mathrm{dL}^{-1}\right)$ e fibrinogênio (g.dL ${ }^{-1}$ ) e hematócrito (\%) em sangue periférico de eqüinos antes (P), 24, 48 e 72 horas após laparotomia em estação concomitante com a realização de enterotomia.

\begin{tabular}{|c|c|c|c|c|}
\hline \multirow[b]{2}{*}{ Parâmetros } & \multicolumn{4}{|c|}{ Valores médios \pm desvio padrão. } \\
\hline & $\mathrm{P}$ & 24 & 48 & 72 \\
\hline Eritrócitos & $7,63^{a} \pm 0,69$ & $8,60^{b} \pm 0,81$ & $8,12^{\mathrm{ab}} \pm 1,06$ & $7,80^{\mathrm{ab}} \pm 0,96$ \\
\hline Hemoglobina & $11,15^{\mathrm{a}} \pm 1,36$ & $12,98^{b} \pm 1,42$ & $11,65^{\mathrm{ab}} \pm 1,66$ & $11,27^{\mathrm{ab}} \pm 1,61$ \\
\hline Hematócrito & $33,28 \pm 3,72$ & $37,42 \pm 6,84$ & $35,28 \pm 5,31$ & $33,28 \pm 5,15$ \\
\hline Leucócitos & $7485,7^{a} \pm 794,6$ & $12128,8^{\mathrm{b}} \pm 512,4$ & $11600,0^{\mathrm{bc}} \pm 1876,1$ & $9900^{c *} \pm 1063,0$ \\
\hline Bastonados & $0,28^{\mathrm{a}} \pm 0,48$ & $7,28^{b} \pm 4,99$ & $3,57^{\mathrm{bc}} \pm 2,82$ & $1,57^{\circ} \pm 1,27$ \\
\hline Segmentados & $55,14^{\mathrm{a}} \pm 5,90$ & $77,42 \pm 10,11$ & $77,0^{*} \pm 7,14$ & $69,42 \pm 8,77$ \\
\hline Proteínas & $6,4^{\mathrm{a}} \pm 0,3$ & $7,24^{b} \pm 0,26$ & $6,81^{\mathrm{ac}} \pm 0,44$ & $6,75^{c} \pm 0,28$ \\
\hline Fibrinogênio & $0,200 \pm 0,03$ & $0,270 \pm 0,04$ & $0,310 \pm 0,08$ & $0,420^{a} \pm 0,07$ \\
\hline
\end{tabular}


A utilização de duas camadas de sutura com poliglactina 910 resultou em uma boa aposição das bordas [22]. Os valores obtidos nas colheitas prévias às intervenções e nas tomadas subseqüentes posicionam-se dentro de limites normais [17,21].

O comportamento dos parâmetros eritrócitos, hematócrito e hemoglobina sofreu variações aparentemente em um mesmo sentido desde a pré-cirurgia até a colheita final com 72 horas. Principalmente no que tange aos eritrócitos, a variação poderia ser esperada em virtude da mobilização esplênica motivada pela manipulação e alterações impostas pelo processo de contenção e agressão cirúrgicas [1]. O comportamento da hemoglobina traçou uma curva semelhante à observada nos eritrócitos.

O número de leucócitos elevou-se em um patamar estatisticamente significativo a partir da primeira colheita pós-operatória que se manteve nos dias subseqüentes. Em outros estudos a contagem leucocitária total não diferiu do perfil basal após a realização de cirurgias abdominais em eqüinos [20]. $\mathrm{O}$ desvio à esquerda registrado por outros autores [1] foi observado no presente estudo no mesmo período citado (24 horas), retornando ao normal até a colheita das 72 horas. Eqüinos tratados após peritonite induzida apresentaram valores de leucócitos entre as 24 e 72 horas dentro de médias fisiológicas. Como estes animais estavam sendo tratados, há possibilidade de que estes valores tenham sido condicionados pela medicação. Os bastonados, no entanto, também sofreram uma elevação no pe- ríodo das 12 horas, retornando aos níveis inferiores nas 24 horas.

As proteínas plasmáticas assim como o hematócrito, independente do processo cirúrgico, devem ser avaliados também sob o aspecto hidratação dos animais, mesmo que não tenha sido estabelecido um jejum hídrico prévio, somente pelo período de preparação, restrição de ingestão, pós-sedativo, e o provável desconforto pós-cirúrgico, a ingestão de água foi com certeza reduzida. Em um estudo, com avaliação hematológica pós-cirúrgica [20], foi observada que uma estabilidade da concentração de proteínas não foi acompanhada pelos valores de hematócrito, eritrócitos e hemoglobina que se elevaram como no presente estudo.

A concentração de fibrinogênio plasmático denota uma elevação, no curso das colheitas. A concentração obtida no estudo aqui descrito elevou-se significativamente, porém sem extrapolar os limites considerados normais Estes dados reforçam outros estudos que responsabilizam intervenções cirúrgicas como laparoscopias ou laparotomias exploratórias como desencadeadoras de rápidas porém significativas reações inflamatórias em nível peritoneal [20].

\section{CONCLUSÕES}

Os parâmetros hematológicos avaliados variaram em relação aos valores basais, caracterizando uma condição de processo inflamatório mas não refletiram nas repercussões clínicas esperadas em um processo infeccioso o qual seria compatível com uma peritonite após intervenção abdominal.

\section{REFERÊNCIAS}

1 Alves G.E.S. 1997. Tratamento da peritonite experimental em eqüinos com a associação de dimetilsulfóxido, heparina e enrofloxacina: estudo clínico, cirúrgico e da patologia. 170 f. Belo Horozonte, MG. Tese (Doutorado em Ciência Animal) Escola de Veterinária, UFMG.

2 Archer R.M., Lindsay W.A., Smith D.F. \& Wilson J.W. 1989. Vascular anatomy of the small cólon. American Journal of Veterinary Research. 50: 893-897.

3 Beck C.A.C. 1993. Avaliação do cloridrato de detomidina na realização de laparotomias exploratórias em eqüinos em estação. 99 f. Porto Alegre, RS. Dissertação (Mestrado em Ciências Veterinárias) Faculdade de Veterinária, Universidade Federal do Rio Grande do Sul.

4 Boles C. 1975. Surgical techniques in equine colic. Journal of South African Veterinary Association. 46: 115-119.

5 Campbell M.D., Bellamy J.E.C. \& Searcy G.P. 1981. Determination of plasma fibrinogen concentration in the horse. American Journal of Veterinary Research. 42: 100-104.

6 Coffman J.R. \& Garner H.E. 1973. Standing laparotomy in the horse. The Equine Practitioner. 54: 53-55.

7 Dart A.J., Snyder J.R., Pascoe J.R., Farver T.B. \& Galuppo L.D. 1992. Abnormal conditions of the descending (small) cólon:102 cases (1979-1989). Journal of American Veterinary Medical Association. 200: 971-978. 
8 Dyson S. 1983. Review of 30 cases of peritonitis in the horse. Equine Veterinary Journal. 15: 25-30.

9 Edwards G.B. 1997. Diseases and surgery of the small cólon. Veterinary Clinics of North America: Equine Practice. 13: 359-375.

10 Hoogmoed L. \& Snyder J.R. 1997. Adjunctive methods in equine gastrointestinal surgery. Veterinary Clinics of North America: Equine Practice. 13: 221-242.

11 Kirkwood B.R. 1988. Essentials of medical statistics. Oxford: Blackwell Scientific, 236p.

12 Lassen E.D. \& Swardson C.J. 1995. Hematology and hemostasis in the horse: normal functions and common abnormalities. Veterinary Clinics of North America - Equine Practice. 11: 351-389.

13 Massone F. 2003. Atlas de Anestesiologia Veterinária. São Paulo:Roca, 172p.

14 Moon P.F \& Suter C.M. 1993. Paravertebral thoracolumbar anaesthesia in 10 horses. Equine Veterinary Journal. 25: 304-308.

15 Parry B. 2003. Normal Clinical Pathology Data. In: Robinson N.E. (Ed). Current Therapy in Equine Medicine. 5nd. edn. St. Louis: Saunders, pp. 870-886.

16 Rhoads W.S., Barton M.H.\& Parks A.H. 1999. Comparison of medical and surgical treatment for impaction of the small cólon in horses: 84 cases (1986-1996). Journal of American Veterinary Medical Association. 214: 1042-1047.

17 Ross M.W. 1991. Standing Abdominal Surgery. Veterinary Clinics of North America - Equine Practice. 7: 627-639.

18 Santschi E.M, Grindem C.B, Tate L. \& Corbett W.T. 1988. Peritoneal fluid analysis in ponies after abdominal surgery. Veterinary Surgery. 17: 6-9.

19 Tyler R.D., Cowell R.L., Clinkenbeard K.D.\& Macallister C.G. 1987. Hematologic values in horses and interpretation of hematologic data. Clinical Pathology. 3: 461-484.

20 Young R.L., Snyder J.R., Pascoe J.R., Olander H.J. \& Hinds D.M. 1991. A comparison of three techniques for closure of pelvic flexure enteromies in normal equine cólon. Veterinary Surgery. 20: 185-189. 